\title{
Characterization of Mutations in the Iron-Sulphur Subunit of Succinate Dehydrogenase Correlating with Boscalid Resistance in Alternaria alternata from California Pistachio
}

\author{
H. F. Avenot, A. Sellam, G. Karaoglanidis, and T. J. Michailides
}

\begin{abstract}
First and fourth authors: Department of Plant Pathology, University of California Davis, Kearney Agricultural Center, 9240 South Riverbend Ave., Parlier 93648; second author: Biotechnology Research Institute, National Research Council of Canada 6100 Royalmount Montreal, PQ, Canada H4P 2R2; and third author: Aristotelian University of Thessaloniki, Faculty of Agriculture, Plant Pathology Laboratory, POB 269, 54006, Thessaloniki, Greece.
\end{abstract}

Accepted for publication 25 February 2008.

\begin{abstract}
Avenot, H. F., Sellam, A., Karaoglanidis, G., and Michailides, T. J. 2008. Characterization of mutations in the iron-sulphur subunit of succinate dehydrogenase correlating with boscalid resistance in Alternaria alternata from California pistachio. Phytopathology 98:736-742.

Thirty-eight isolates of Alternaria alternata from pistachio orchards with a history of Pristine (pyraclostrobin + boscalid) applications and displaying high levels of resistance to boscalid fungicide (mean $\mathrm{EC}_{50}$ values $>500 \mu \mathrm{g} / \mathrm{ml}$ ) were identified following mycelial growth tests. A cross-resistance study revealed that the same isolates were also resistant to carboxin, a known inhibitor of succinate dehydrogenase (Sdh). To determine the genetic basis of boscalid resistance in A. alternata the entire iron sulphur gene $(A a S d h B)$ was isolated from a fungicide-sensitive isolate. The deduced amino-acid sequence showed high similarity with iron sulphur proteins (Ip) from other organisms. Comparison of AaSdhB full sequences from sensitive and resistant isolates revealed that a highly
\end{abstract}

ABSTRACT

Alternaria late blight of pistachio caused by Alternaria spp. in the alternata, tenuissima, and arborescens species-groups is one of the most common fungal diseases of pistachio in California affecting both foliage and fruit (25). Control of the disease is a difficult task and requires a combination of management approaches and multiple fungicidal sprays. Quinone outside Inhibitors fungicides $\left(\mathrm{Q}_{0} \mathrm{Is}\right)$ have become a key component of disease management strategies in California due to their excellent control efficacy and yield benefits. However, after only a few years of $\mathrm{Q}_{\mathrm{o}}$ Is use on pistachio crops the development of resistant populations of Alternaria spp., caused by a mutation at position 143 (G143A) in the cytochrome b-target-encoding gene, has compromised their use $(2,19,31)$.

As a strategy to manage the widespread resistance to $\mathrm{Q}_{0}$ Is in California pistachio orchards the new carboxamide fungicide, boscalid, has recently been introduced in a pre-packed mixture with the $\mathrm{Q}_{\mathrm{o}} \mathrm{I}$ pyraclostrobin. This mixture is used particularly against Alternaria late blight. Besides boscalid, the group of carboxamide fungicides also contains other compounds such as carboxin, flutolanil, benodanil, or furametpyr (6). These compounds are exceptionally active against Basidiomycete fungi and have been successfully used for many years in agriculture to

Corresponding authors: H. F. Avenot and T. J. Michailides E-mail addresses: havenot@uckac.edu or themis@uckac.edu

doi:10.1094/PHYTO-98-6-0736

(C) 2008 The American Phytopathological Society conserved histidine residue (codon CAC in sensitive isolates) was converted to either tyrosine (codon TAC, type I mutants) or arginine (codon CGC, type II mutants) at position 277. In other fungal species this residue is involved in carboxamide resistance. In this study, 10 and 5 mutants were of type I and type II respectively, while 23 other resistant isolates (type III mutants) had no mutation in the histidine codon. The point mutation detected in type I mutants was used to design a pair of allele-specific polymerase chain reaction (PCR) primers to facilitate rapid detection. A PCR-restriction fragment length polymorphism (RFLP) assay in which amplified gene fragments were digested with AciI was successfully employed for the diagnosis of type II mutants. The relevance of these modifications in A. alternata AaSdhB sequence in conferring boscalid resistance is discussed.

Additional keywords: complex mitochondrial II, fungicide resistance, PCR-based assays. control bunt and smut diseases of cereals $(13,23,30)$. Unlike most of these carboxamide fungicides, boscalid has an unusual fungicidal profile. It is highly effective against plant pathogens belonging to the Ascomycetes and the Deuteromycetes, such as Botrytis cinerea, and species of Sclerotinia, Alternaria, and Monilinia, as well as powdery mildews and other pathogens in fruit, vegetables, and vines $(20,28,29)$.

Carboxamide fungicides are single-site inhibitors and their target is the succinate ubiquinone reductase or succinate dehydrogenase $(\mathrm{Sdh})$ complex in the respiratory chain $(3,17)$. This enzyme complex is a functional part of the tricarboxylic acid cycle and the mitochondrial electron transport chain and catalyzes both the oxidation of succinate to fumarate and the reduction of quinone. The Sdh complex consists of four subunits, a flavoprotein $(\mathrm{Fp})(\mathrm{Sdh} A)$, an iron sulfur protein (Ip) (SdhB), and two membrane-anchored proteins ( $\mathrm{SdhC}$ and $\mathrm{SdhD})$. The Fp and Ip subunits form the soluble part of the complex and possess succinate dehydrogenase activity. The $\mathrm{SdhC}$ and $\mathrm{SdhD}$ subunits anchor $\mathrm{Fp}$ and $\mathrm{Ip}$ to the membrane and have quinone reduction activity $(13,16)$.

The boscalid-containing product Pristine (BASF Corporation, Research Triangle Park, NC) was registered for use against Alternaria late blight of pistachio in 2003. However, after only 2 years of use, reductions in the efficacy of this product in the field have prompted concerns over development of resistance to boscalid, particularly in light of the widespread resistance to $Q_{0}$ Is. Studies carried out to test the control efficacy of boscalid against the strobilurin-resistant strains of the pathogen and to determine the sensitivity profile of pathogenic isolates to boscalid, demonstrated 
the high efficacy of boscalid in controlling strobilurin-resistant strains. However, they also revealed the existence of A. alternata isolates expressing a high level of resistance to boscalid $(1,2)$.

As was the case with resistance to $\mathrm{Q}_{\mathrm{o}} \mathrm{Is}$, the rapid appearance of boscalid resistant populations of A. alternata in pistachio orchards when boscalid-containing fungicides are used to combat Alternaria late blight, indicates that it is imperative to monitor boscalid resistance in this fungus infecting pistachio. Elucidation of the molecular basis of this resistance will enable the development of quick methods for use in monitoring studies. Studies on the molecular mechanisms responsible for the acquisition of resistance to boscalid analog-fungicides in some resistant populations of bacteria and Basidiomycete and Ascomycete fungi have shown that mutations in conserved regions of the genes $S d h B, S d h C$, and $S d h D$ encoding the boscalid targets result in reduced sensitivity $(3,7,8,9,13,15,22,26,30)$. In fact, single amino acid substitutions found in the $\mathrm{SdhB}$ subunit within the third Cys-rich cluster that takes part in binding of iron-sulfur centers of Ustilago maydis $(3,15)$, Pleurotus ostreatus (10), Mycosphearella graminicola (26), and Paracoccus denitrificans (21) have been associated with increased resistance.

Resistant strains are frequently cross-resistant to structurally related chemicals or to chemicals with similar modes of action (5). For instance, cross-resistance has been demonstrated for flutolanil and carboxin both members of the carboxamide group (13). The fact that boscalid, carboxin, and flutolanil belong to the same chemical group infers that there is cross resistance to these compounds in A. alternata and that boscalid resistance in this fungus is governed by mutations in the target genes similar to those for carboxin and flutolanil resistance.

The objectives of the current study were to (i) establish the level of sensitivity to boscalid of A. alternata field isolates collected from 2006 to 2007 from pistachio orchards treated for at least three consecutive years with the boscalid-containing fungicide Pristine, (ii) investigate the cross resistance patterns between boscalid and carboxin in these isolates, (iii) elucidate the molecular mechanism responsible for boscalid resistance in A. alternata populations by isolating a putative iron sulfur gene and determining if mutations in this gene are responsible for boscalid resistance, and (iv) develop polymerase chain reaction (PCR)based methods for the rapid identification of resistant mutants.

\section{MATERIALS AND METHODS}

Origin and collection of single spore isolates. All of the $A$. alternata isolates used in this study are listed in Table 1. They were isolated from pistachio leaves showing putative Alternaria infection and collected during the pistachio growing seasons from 2006 to 2007 from different pistachio orchards where boscalid had been used in mixture with pyraclostrobin (Pristine) for three or four consecutive years with two or three spray applications per season. Ten A. alternata boscalid-resistant and -sensitive isolates collected from an orchard located in Kern County that had been treated with boscalid (again in Pristine) for over 2 years, were also included in the study (1). Conidial isolates were obtained according to the procedure described by Pryor and Michailides (25). Single spore isolates were maintained on potato dextrose agar (PDA) at $4^{\circ} \mathrm{C}$ until use.

Media and fungicide sensitivity determination. Fungicides used in the study were pure (a.i., 98.4\%) technical grade boscalid (BASF Corporation, Research Triangle Park, NC) and a commercial formulation of carboxin (Vitavax 34 FF, Chemtura Corp, Middleburry, CT). Technical grade boscalid was dissolved in acetone to provide stock solutions containing 10 and $50 \mathrm{mg}$ a.i. $/ \mathrm{ml}$. Autoclaved PDA was cooled to $50^{\circ} \mathrm{C}$ and boscalid was added to obtain concentrations of $0,0.001,0.005,0.01,0.05,0.1,0.5,1,5$, $10,50,100,250$, and $500 \mu \mathrm{g} / \mathrm{ml}$. The concentration of acetone in all PDA media never exceeded $1 \mathrm{ml} /$ liter. No fungicide was added to the control medium. Tests for each isolate were repeated two times per fungicide concentration.

Mycelial plugs of each isolate were removed, with the aid of a 5-mm-diameter cork borer, from the colony margins of actively growing 72-h-old colonies on PDA and placed upside down on the center of 30 petri dishes containing the fungicide-amended or unamended media. Cultures were incubated at $24^{\circ} \mathrm{C}$ in the dark for 7 days. Radial growth of each isolate was measured (minus the diameter of inoculation plug) after 7 days by calculating the mean of two perpendicular colony diameters and expressed as a percentage of the mean diameter of the untreated control. The $\mathrm{EC}_{50}$ value (effective concentration that reduces the mycelial growth by $50 \%$ ) of each isolate was calculated by regressing the relative inhibition of growth against the $\log _{10}$ fungicide concentration. Depending on their sensitivity to boscalid, isolates were graded into two classes. Isolates classified as sensitive $(\mathrm{S})$ had $\mathrm{EC}_{50}$ values ranging between 0 and $5 \mu \mathrm{g} / \mathrm{ml}$, and highly resistant $(\mathrm{HR})$ isolates had an $\mathrm{EC}_{50}$ value higher than $100 \mu \mathrm{g} / \mathrm{ml}$.

Determination of sensitivity to carboxin was carried out on $A$. alternata isolates that were either identified as boscalid-resistant or -sensitive. Measurements of sensitivity, in terms of $\mathrm{EC}_{50}$ values, were based on inhibition of mycelial growth. For this purpose, autoclaved PDA was amended with $0,0.1,0.5,1,5,10$, $50,100,200,300$, and $500 \mu \mathrm{g} / \mathrm{ml}$ a.i. carboxin. The sensitivity determination procedure was similar to that previously described for boscalid.

DNA manipulations. Genomic DNA was extracted from mycelium of A. alternata using the FastDNA kit (Qbiogene, Carlsbad, CA) according to the manufacturer's instructions.

Primer set 1 (Table 2) was designed by aligning conserved sequences spanning the cysteine-rich clusters associated with the S1 and S3 iron-sulphur redox centers of the succinate dehydrogenase gene of A. brassiccicola and Stagonospora nodorum (syn. Phaeosphaeria nodorum) (accession number SNOG_03351). This primer set was used to amplify the putative $S d h B$ gene fragment from A. alternata genomic DNA from the boscalidsensitive strain AaY16. PCR reactions were performed in a $50-\mu 1$ volume containing $50 \mathrm{ng}$ of DNA, $50 \mathrm{mM} \mathrm{KCl}, 1.5 \mathrm{mM} \mathrm{MgCl}_{2}$, $10 \mathrm{mM}$ Tris- $\mathrm{HCl}$ (pH 9.0), 0.1\% Triton X-100, $0.2 \mathrm{mM}$ of each dNTP (Promega, Madison, WI), $0.2 \mu \mathrm{M}$ of each primer, and 1 unit of Pfu DNA polymerase (Stratagene, La Jolla, CA). PCR was carried out in a Mastercycler (Eppendorf, Hamburg) with an initial pre-heat for $3 \mathrm{~min}$ at $95^{\circ} \mathrm{C}$, followed by 40 cycles of denaturation at $94^{\circ} \mathrm{C}$ for $40 \mathrm{~s}$, annealing at $51^{\circ} \mathrm{C}$ for $50 \mathrm{~s}$, extension at $72^{\circ} \mathrm{C}$ for $1 \mathrm{~min}$, and terminated with a final extension at $72^{\circ} \mathrm{C}$ for $10 \mathrm{~min}$. PCR products were separated by electrophoresis in $1.2 \%$ agarose gel in Tris-acetate (TAE) buffer. The PCR products from each isolate were purified from gel using the Geneclean Kit (MP Biomedicals, LLC., Solon, OH), cloned into a pGEM-T Easy vector (Promega, Madison, WI) and subsequently sequenced. The $5^{\prime}$ and $3^{\prime}$ regions of $A$. alternata $S d h B$ gene $(A a S d h B)$ were obtained by PCR amplification using two sets of primer (Sets 2 and 3) designed from both the obtained fragment and conserved sequence of corresponding regions in A. brassicicola homologous gene (Table 2). PCR products were cloned and sequenced as described above.

The WoLF PSORT prediction program was used to predict the cellular localization of AaSdhB.

Allele-specific PCR (AS-PCR) and PCR-restriction fragment length polymorphism (RFLP) assays. In this study, the sequence polymorphism analysis of the $A a S d h B$ gene revealed that some A. alternata boscalid resistant isolates had a single point mutation from $\mathrm{C}$ (CAC in sensitive isolates) to $\mathrm{T}$ (TAC in resistant isolates) causing a change of histidine to a tyrosine at codon position 277 (H277Y) of the AaSdhB. Based on this point mutation, a primer pair ADF1/ADR2 (primer set 5; Table 2) was designed to specifically prime the $A a S d h B$ gene of resistant isolates having this mutation (type I mutants). The reverse primer 
ADR2 was designed to match the putative point mutation T277 at the $3^{\prime}$ end of the primer. A base mismatch located at the fourth base position from the $3^{\prime}$ end was incorporated into the primer to enhance the specificity of the amplification $(18,24)$. The primer pair was expected to generate a 250-bp PCR product from resistant isolates only. DNA extracted from the 10 type I mutants, and 3 boscalid-sensitive and 3 boscalid-resistant isolates, without the $\mathrm{C}$ to $\mathrm{T}$ mutation were used in the AS-PCR assay. PCR amplifications were performed in a $50-\mu \mathrm{l}$ volume containing $2 \mu \mathrm{l}$ of isolated genomic DNA, $0.2 \mu \mathrm{M}$ of each primer, $0.2 \mathrm{mM}$ of each dNTP, $2.5 \mathrm{mM} \mathrm{MgCl}$, $1 \times$ Promega (Madison, WI) Taq polymerase buffer, and $2 \mathrm{U}$ of Promega Taq polymerase. The PCR amplifications were performed using the following parameters: an initial preheat for $3 \mathrm{~min}$ at $95^{\circ} \mathrm{C}$, followed by 40 cycles of denaturation at $94^{\circ} \mathrm{C}$ for $40 \mathrm{~s}$, annealing at $65.5^{\circ} \mathrm{C}$ for $40 \mathrm{~s}$, extension at $72^{\circ} \mathrm{C}$ for $1 \mathrm{~min}$, and a final extension at $72^{\circ} \mathrm{C}$ for 10 $\mathrm{min}$. The amplicons of each isolate from the AS-PCR assay were analyzed by $1.5 \%$ agarose gels in $1 \times$ Tris-acetate (TAE) buffer.

In the current study, an A-to-G mutation occurred at nucleotide 977 in the $A a S d h B$ sequence in several other A. alternata mutants (type II mutants) creating an AciI restriction enzyme site. Primer, set 6 (Table 2), was designed to amplify mutation-containing frag- ments that were subsequently digested with the enzyme AciI (New England BioLabs Inc., Beverly, MA) according to the manufacturer's instructions. Digestion products were then separated on a $2 \%$ agarose gel in $1 \times$ TAE buffer.

\section{RESULTS}

Sensitivity of $A$. alternata isolates to boscalid and cross resistance to carboxin. Among the 46 isolates tested, 38 were highly resistant to boscalid with $\mathrm{EC}_{50}$ values higher than $500 \mu \mathrm{g} / \mathrm{ml}$. Only eight isolates were found to be sensitive to boscalid with $\mathrm{EC}_{50}$ values between 0.13 and $0.56 \mu \mathrm{g} / \mathrm{ml}$ (Table 1). Notably, the sensitive isolates were able to grow slightly at some higher concentrations of boscalid but growth remained strongly inhibited compared to that observed for the resistant isolates at the same conditions.

All the 38 boscalid-resistant and the 8 boscalid-sensitive isolates detected were examined for cross-resistance to the carboxamide fungicide carboxin. The corresponding $\mathrm{EC}_{50}$ values for carboxin of these isolates are shown in Table 1. The mean $\mathrm{EC}_{50}$ values to carboxin for all wild-type boscalid-sensitive isolates was $15.53 \mu \mathrm{g} / \mathrm{ml}( \pm 2.80)$ and was higher than that obtained for the

TABLE 1. Characteristics and sensitivity to boscalid and carboxin of the Alternaria alternata isolates from pistachio orchards used in this study

\begin{tabular}{|c|c|c|c|c|c|}
\hline Isolate & Location & Year of isolation & Number of years of boscalid exposure & $\mathrm{EC}_{50}$ boscalid $(\mu \mathrm{g} / \mathrm{ml})^{\mathrm{a}}$ & $\mathrm{EC}_{50}$ carboxin $(\mu \mathrm{g} / \mathrm{ml})$ \\
\hline AaY16 & Kern County, CA & 2005 & 2 & 0.28 & 13.21 \\
\hline Aa4 & Kern County, CA & 2005 & 2 & 0.26 & 11.27 \\
\hline Aa127 & Kern County, CA & 2005 & 2 & 0.56 & 18.49 \\
\hline $\mathrm{Aa} 20$ & Kern County, CA & 2005 & 2 & $>500$ & 77.37 \\
\hline $\mathrm{Aa} 22$ & Kern County, CA & 2005 & 2 & $>500$ & 105.81 \\
\hline Aa29 & Kern County, CA & 2005 & 2 & $>500$ & 54.41 \\
\hline Aa65 & Kern County, CA & 2005 & 2 & $>500$ & 51.23 \\
\hline Aa111 & Kern County, CA & 2005 & 2 & $>500$ & 43.58 \\
\hline Aa122 & Kern County, CA & 2005 & 2 & $>500$ & 65.79 \\
\hline AaY1 & Kern County, CA & 2005 & 2 & $>500$ & 38.06 \\
\hline $\mathrm{Aa} 4 \mathrm{y}$ & Kern County, CA & 2006 & 3 & 0.22 & 13.19 \\
\hline Aa35 & Kern County, CA & 2006 & 3 & 0.13 & 18.40 \\
\hline Aa6 & Kern County, CA & 2006 & 3 & 0.28 & 18.67 \\
\hline Aa61 & Kern County, CA & 2006 & 3 & 0.45 & 15.67 \\
\hline Aa62 & Kern County, CA & 2006 & 3 & 0.37 & 15.08 \\
\hline $\mathrm{Aa} 2$ & Kern County, CA & 2006 & 3 & $>500$ & 55.67 \\
\hline $\mathrm{Aa} 26$ & Kern County, CA & 2006 & 3 & $>500$ & 46.64 \\
\hline Aa51 & Kern County, CA & 2006 & 3 & $>500$ & 74.67 \\
\hline $\mathrm{Aa} 44$ & Kern County, CA & 2006 & 3 & $>500$ & 51.51 \\
\hline Aa41 & Kern County, CA & 2006 & 3 & $>500$ & 54.03 \\
\hline Aa13 & Kern County, CA & 2006 & 3 & $>500$ & 46.41 \\
\hline Aa48 & Kern County, CA & 2006 & 3 & $>500$ & 109.10 \\
\hline $\mathrm{Aa} 3$ & Kern County, CA & 2006 & 3 & $>500$ & 57.32 \\
\hline Aa68 & Kern County, CA & 2006 & 3 & $>500$ & 57.82 \\
\hline $\mathrm{Aa} 40$ & Kern County, CA & 2006 & 3 & $>500$ & 64.80 \\
\hline Aa10 & Kern County, CA & 2006 & 3 & $>500$ & 98.53 \\
\hline $\mathrm{Aa} 32$ & Kern County, CA & 2006 & 3 & $>500$ & 43.73 \\
\hline Aa54 & Kern County, CA & 2006 & 3 & $>500$ & 68.71 \\
\hline Aa19 & Kern County, CA & 2006 & 3 & $>500$ & 80.92 \\
\hline Aa94 & Kern County, CA & 2007 & 4 & $>500$ & 62.17 \\
\hline Aa100 & Kern County, CA & 2007 & 4 & $>500$ & 53.18 \\
\hline Aa105 & Kern County, CA & 2007 & 4 & $>500$ & 63.67 \\
\hline Aa102 & Kern County, CA & 2007 & 4 & $>500$ & 28.95 \\
\hline Aa103 & Kern County, CA & 2007 & 4 & $>500$ & 41.97 \\
\hline Aa37 & Kern County, CA & 2006 & 3 & $>500$ & 45.38 \\
\hline Aa45 & Kern County, CA & 2006 & 3 & $>500$ & 53.51 \\
\hline Aa33 & Kern County, CA & 2006 & 3 & $>500$ & 71.31 \\
\hline Aa58 & Kern County, CA & 2006 & 3 & $>500$ & 80.29 \\
\hline Aa65n & Nichols, Tulare County, CA & 2007 & 4 & $>500$ & 34.52 \\
\hline Aa67n & Nichols, Tulare County, CA & 2007 & 4 & $>500$ & 57.68 \\
\hline Aa72n & Nichols, Tulare County, CA & 2007 & 4 & $>500$ & 99.81 \\
\hline $\mathrm{Aa} 48 \mathrm{o}$ & Orandi, Tulare County, CA & 2007 & 4 & $>500$ & 40.44 \\
\hline $\mathrm{Aa} 260$ & Orandi, Tulare County, CA & 2007 & 4 & $>500$ & 41.17 \\
\hline Aa19o & Orandi, Tulare County, CA & 2007 & 4 & $>500$ & 52.02 \\
\hline Aa8o & Orandi, Tulare County, CA & 2007 & 4 & $>500$ & 136.26 \\
\hline Aa29ob & Orandi, Tulare County, CA & 2007 & 4 & $>500$ & 98.83 \\
\hline
\end{tabular}

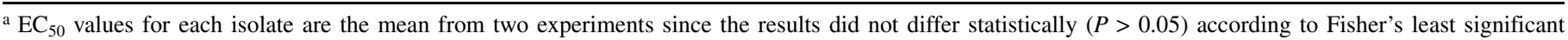
difference test. 
same isolates in the presence of boscalid for which the mean $\mathrm{EC}_{50}$ had a value of $0.32 \pm 0.14 \mu \mathrm{g} / \mathrm{ml}$. For all the boscalid-resistant mutants, the mean $\mathrm{EC}_{50}$ value for carboxin was $63.35( \pm 23.70)$ $\mu \mathrm{g} / \mathrm{ml}$ and was much lower compared to the mean $\mathrm{EC}_{50}$ value (mean $\mathrm{EC}_{50}>500 \mu \mathrm{g} / \mathrm{ml}$ ) obtained in the presence of boscalid. Furthermore, it could be noted that at higher concentrations of carboxin, the boscalid resistant-isolates were strongly inhibited. For instance, at $500 \mu \mathrm{g} / \mathrm{ml}$ of carboxin, the percentage of inhibition ranged from 75.00 to $90.74 \%$ (mean $=85.68 \%$ ), whereas at the same concentration of boscalid, the same isolates were weakly inhibited (mean percentage of inhibition value $=17.94 \%$ ).

Cloning of a succinate dehydrogenase iron sulfur gene from A. alternata. Primer pair, set 1 , designed on the basis of fungal SdhB Ip from A. brassicicola and $S$. nodorum (Syn Phaeosphaeria nodorum) was successfully used to amplify a 602-bp fragment from the genomic DNA of A. alternata AaY16 a boscalid-sensitive strain. This fragment was cloned and sequenced. The resulting sequence was used to search the GenBank nonredundant database using the BLASTX algorithm. Significant matches were obtained with SdhB Ip orthologues from several filamentous fungi. This fragment contains the three conserved cysteine-rich clusters associated with the iron-sulphur centers S1, $\mathrm{S} 2$, and S3. The complete coding sequence (accession no. EU178851) was obtained by PCR amplification using primer set 2 and 3 designed both on the basis of the obtained DNA fragment and $A$. brassicicola SdhB DNA sequence.

The assembled DNA sequence contains an open reading frame (ORF) of 306 amino acids interrupted by three putative introns. $A$. alternata $\mathrm{SdhB}(\mathrm{AaSdhB})$ was highly similar to the well-characterized mitochondrial iron sulfur proteins of succinate dehy- drogenase of Saccharomyces cerevisae (72\% identity), Mycosphaerella graminicola (82\%), and Ustilago maydis (63\%).

The three Cys-rich clusters of AaSdhB responsible for ligating the iron-sulphur centers (S1, S2, and S3) are highly conserved. These clusters were identified at amino-acid positions 125 to 144 , 217 to 229, and 274 to 286, respectively (Fig. 1). Subcellular localization prediction using the WoLF PSORT program indicates that AaSdhB contains an N-terminal mitochondrial targeting sequence, which is in accordance with the function of this protein.

Sequence comparison of $\mathrm{AaSdhB}$ gene between boscalidsensitive and boscalid-resistant $A$. alternata isolates. The complete nucleotide sequence of the $A a S d h B$ gene was determined for seven boscalid-resistant isolates (Aa20, Aa22, Aa29, Aa111, AaY1, Aa122, and Aa65) and three boscalid-sensitive isolates (Aa4, Aa127, and AaY16). The Genbank accessions numbers of these sequences are EU178851 to EU178857. Comparison of the DNA sequences of sensitive and resistant isolates revealed that the $\mathrm{C}$ at position 996 in the boscalid-resistant isolates Aa20, Aa22, Aa29, and Aa111 was replaced by $\mathrm{T}$ resulting in $\mathrm{H} 277 \mathrm{Y}$ substitution in the third iron-sulphur center S3. The nucleotide sequences of $A a S d h B$ of the boscalid-resistant isolates (AaY1, Aa122, and Aa65) were identical to those of the wild-type sensitive isolates (Table 3).

To further clarify the relationship between the genotype (presence of the H277Y mutation) and the phenotype (resistance to boscalid) this region was sequenced for the remaining boscalidresistant isolates identified in this study. A primer set 4 was designed to amplify the region containing the mutation from genomic DNA. PCR amplifications were carried out with highfidelity $P f u$ DNA polymerase and individual 200-bp PCR prod-

TABLE 2. Primer sets used for amplification of the AaSdhB gene from Alternaria alternata genomic DNA

\begin{tabular}{|c|c|c|c|}
\hline Primer set & $5^{\prime}$ primer & $3^{\prime}$ primer & Amplified DNA fragment ${ }^{\mathrm{a}}$ \\
\hline 1 & TACGAGCTCGACCTCAACAAGAC & CTCGGCAACGCGGGGTTCAGTC & +341 to +1049 \\
\hline 2 & GTGGCGTCGAAGGGCCGAAGAAGCCG & CAGCATCATGGGTCCGGTCTTGTTGA & -33 to +349 \\
\hline 3 & TACTGGTGGAACCAGGAGGAGTA & CATACCACTCTAGGTGAAG & +856 to +1130 \\
\hline 4 & CGACGGACTCTACGAATGC & GCATGTCCTTGAGCAGTTGAG & +801 to +1020 \\
\hline 5 & AAGCTCGACGGACTCTACGAATGC & CTTGAGCAGTTGAGAATGGAGTA & +796 to +1013 \\
\hline 6 & AAGGAAGATCGCAAGAAGCTC & AATGGCTAGCGCAGGGTTCA & +781 to +1050 \\
\hline 7 & AAGCTCGACGGACTCTACGAATGC & CTTGAGCAGTTGAGAATGGAGTG & +796 to +1013 \\
\hline
\end{tabular}

a Fragment numbering corresponds to nucleotide positions in the $A a S d h B$ gene, with the first nucleotide of the start codon considered as position +1 .

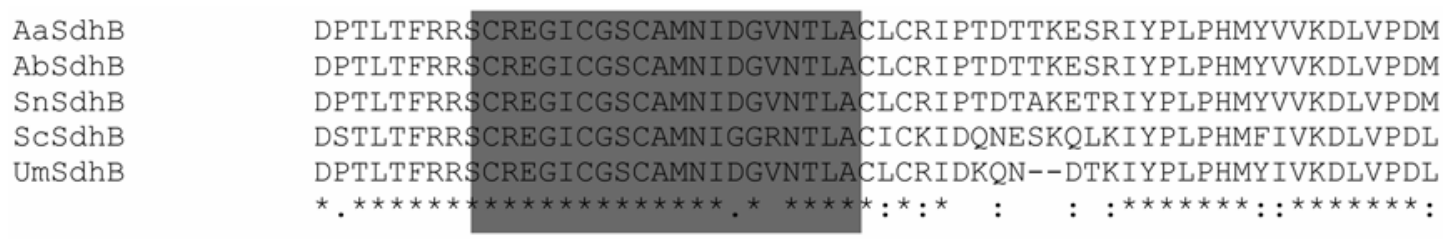

AasdhB

$\mathrm{AbSdhB}$

SnSdhB

$\mathrm{ScSdhB}$

UmSdhB

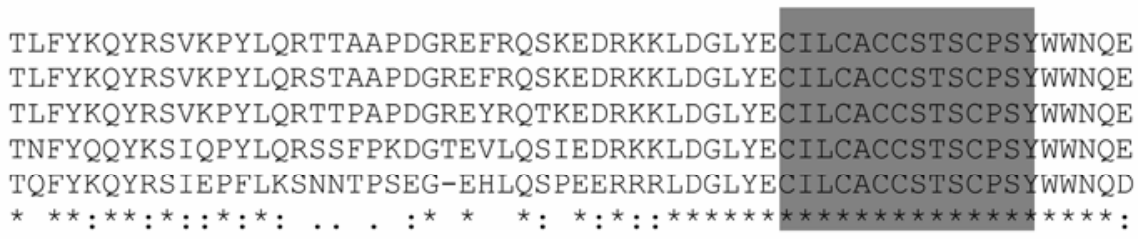

AasdhB

$\mathrm{AbSdhB}$

EYLGPAVLLQSYRWIADSRDEKKAERQDALNNSMS LYRCHTILNCSRTCPKGLNPALAIA EYLGPAVLLQSYRWIADSRDEKKAERQDALNNSMS LYRCHT I LNCSRTCPKGLNPALAIA

SnSdhB EYLGPAVLLQSYRWIADSRDEKLAERQDALNNSMSLYRCHTILNCSRTCPKGLNPALAIA

$\operatorname{ScSdhB}$ QYLGPAVLMQAYRWLIDSRDQATKTRKAMLNNSMSLYRCHT IMNCTRTCPKGLNPGLAIA

UmSdhB EYLGPAVLMQAYRWMADSRDDFGEERRQKLENTFSLYRCHTIMNCSRTCPKNLNPGKAIA $: * * * * * * *{ }^{*}: * * *: * * * *: \quad *{ }^{*}:{ }^{*}::^{* * * * * * * *}: * *: * * * * *, * * * . * * *$

Fig. 1. Comparison of the amino acid region, containing the three cysteine-rich clusters (shaded regions) of AaSdhB of Alternaria alternata with similar regions of SdhB subunits from other organisms. The highly conserved histidine residues within the third cysteine cluster are in bold type. Aa, A. alternata; Ab, Alternaria brassicicola; Sn, Stagonopora nodorum (Syn. Phaeosphaeria nodorum); Sc, Saccharomyces cerevisiae; and Um, Ustilago maydis. 
ucts were purified and sequenced directly. Comparison of the partial sequences from amplified products of the $A a S d h B$ alleles from boscalid-resistant isolates with that of the wild-type sensitive isolates revealed the presence of the mutation $\mathrm{H} 277 \mathrm{Y}$ in six resistant isolates (Aa45, Aa65n, Aa26o, Aa48o, Aa67n, and Aa72n). In five other isolates (Aa33, Aa58, Aa190, Aa8o, and Aa29bo) an A-to-G mutation occurred at position 997 affecting the conserved histidine residue and leading to an $\mathrm{H} 277 \mathrm{R}$ substitution (Table 3). Among the strains analyzed, 23 fungicideresistant isolates had no mutation in this region of $A a S d h B$, or in the remaining portion of the ORF (data not shown). The boscalidresistant isolates described in this study were divided into three groups based on their sensitivity to boscalid and the presence/ absence of mutation in AaSdhB (Table 3).

Molecular diagnosis of boscalid resistant isolates mutated in $\boldsymbol{A a S d h B}$. At a high annealing temperature $\left(65.5^{\circ} \mathrm{C}\right)$, the allelespecific primer pair ADF1 + ADR2 (primer set 5) amplified the expected 250-bp DNA fragment from the DNA extracted from the 10 boscalid-resistant type I mutants (Aa20, Aa29, Aa22, Aa45, Aa111, Aa65n, Aa48o, Aa67n, Aa26o, and Aa72n), but not from any of the eight sensitive A. alternata isolates and those of type II and III resistant mutants (Fig. 2). This process indicated that the allele-specific PCR primer pair ADF1 + ADR2 was specific only to boscalid-resistant type I mutants. A second pair of primers (primer set 7), with ADS R2 having its last base at the 3 '-end matching the wild type nucleotide on which the putative point mutation was located in type I mutants and a base mismatch at the fourth base from the $3^{\prime}$ end, was designed and successfully used to detect both the sensitive wild-type and the nontype I mutants alleles (data not shown).

Primer set 6, amplified the expected 300-bp DNA fragment for all boscalid-resistant and -sensitive isolates tested. The PCR products were then treated using a mutation specific enzyme AciI. The PCR products from type II resistant mutants carrying the mutated sequence CGC at position 997 were digested into 210and 90-bp fragments, whereas products from sensitive isolates and other mutants remained undigested (Fig. 3).

\section{DISCUSSION}

The development of resistance to boscalid has been reported only in a small number of fungi, A. alternata from pistachio and Botrytis cinerea from grapes and strawberries (28). In contrast, resistance to structurally related chemicals, such as carboxin, is a pervasive phenomenon $(3,10,13,15,22,26,30)$. As expected for compounds of the same chemical class, positive cross-resistance has been demonstrated in this group for flutolanil and carboxin (13). In the current study, field isolates of A. alternata were tested for sensitivity to boscalid. Slight growth of wild type isolates was observed at high doses of boscalid. This could be attributed to the rich PDA medium used in the assay. It was previously shown that complete growth inhibition of sensitive isolates is sometimes not possible in boscalid petri dish assays using rich media $(20,27,29)$. Despite this, the Alternaria isolates in this study were easily and clearly distinguished as sensitive and highly resistant to boscalid.

In this study, the response of $A$. alternata boscalid-resistant and -sensitive isolates in the presence of carboxin was also examined. Results showed that wild-type isolates were weakly affected by

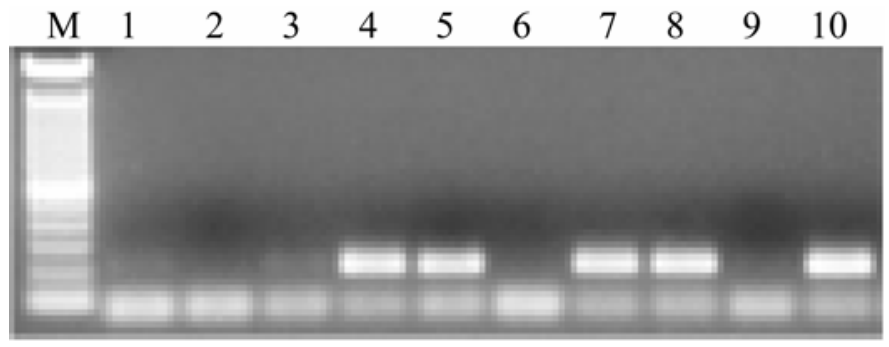

Fig. 2. Specificity of allele-specific polymerase chain reaction (PCR) primer set 3 for detection of boscalid-resistant type 1 mutants of Alternaria alternata. Amplification products were obtained using genomic DNA from mutants type I Aa20, Aa29, Aa111, Aa26o, and Aa65n (lanes 4, 5, 7, 8, and 10, respectively), sensitive isolates Aa4 and Aa127 (lanes 1 and 2, respectively), and mutants type II Aa33 and Aa58 (lanes 3 and 6, respectively) and other mutant Aa65 (lane 9). M lane was loaded with a 100-bp DNA ladder (Invitrogen, Carlsbad, CA).

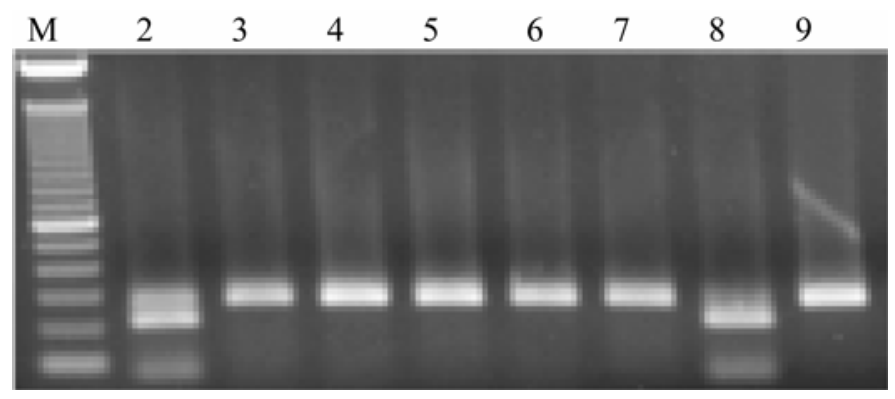

Fig. 3. Restriction fragment length polymorphism (RFLP) analysis of AciIdigested 300-bp polymerase chain reaction (PCR) products corresponding to the portion of the $A a S d h B$ gene generated by the primer set 6: Amplification products were obtained using genomic DNA from Alternaria alternata mutants type II Aa33 (lane 2) and Aa8o (lane 8), sensitive isolates Aa4 (lane 3) and Aa127 (lane 4), mutants type I Aa20 (lane 5) and Aa29 (lane6), and mutants type III Aa65 (lane 7), and Aa40 (lane 9). M lane was loaded with a 100-bp DNA ladder (Invitrogen, Carlsbad, CA).

TABLE 3. Nucleotide mutations and deduced alterations in the iron sulphur AaSdhB from boscalid-resistant field isolates of Alternaria alternata

\begin{tabular}{|c|c|c|c|c|}
\hline Isolate & Phenotype & Mutation at codon 277 & Mutation type & Type of mutant \\
\hline $\mathrm{Aa} 22$ & Highly resistant (HR) & TAC & $\mathrm{H}$ to $\mathrm{Y}$ & $\mathrm{I}$ \\
\hline $\mathrm{Aa} 45$ & HR & TAC & $\mathrm{H}$ to $\mathrm{Y}$ & \\
\hline Aa111 & HR & TAC & $\mathrm{H}$ to $\mathrm{Y}$ & \\
\hline Aa65n & HR & TAC & $\mathrm{H}$ to $\mathrm{Y}$ & \\
\hline Aa48o & HR & TAC & $\mathrm{H}$ to $\mathrm{Y}$ & \\
\hline Aa67n & HR & TAC & $\mathrm{H}$ to $\mathrm{Y}$ & \\
\hline Aa26o & HR & TAC & $\mathrm{H}$ to $\mathrm{Y}$ & \\
\hline Aa72n & HR & TAC & $\mathrm{H}$ to $\mathrm{Y}$ & \\
\hline Aa20 & HR & TAC & $\mathrm{H}$ to $\mathrm{Y}$ & \\
\hline Aa29 & HR & TAC & $\mathrm{H}$ to $\mathrm{Y}$ & \\
\hline Aa33 & HR & $\mathrm{CGC}$ & $\mathrm{H}$ to $\mathrm{R}$ & II \\
\hline Aa58 & HR & CGC & $\mathrm{H}$ to $\mathrm{R}$ & \\
\hline Aa19o & HR & CGC & $\mathrm{H}$ to $\mathrm{R}$ & \\
\hline Aa8o & HR & $\mathrm{CGC}$ & $\mathrm{H}$ to $\mathrm{R}$ & \\
\hline Aa29bo & HR & CGC & $\mathrm{H}$ to $\mathrm{R}$ & \\
\hline $\mathrm{n}^{\mathrm{a}}=23$ & HR & none & $?$ & III \\
\hline
\end{tabular}

a Among the A. alternata-resistant mutants identified 23 had no mutation in the AaSdhB sequence. 
carboxin alone. This lack of activity against Alternaria was not entirely unexpected as previous studies showed that the efficacy of carboxin towards complex II varies between organisms, with Ascomycetes being generally less sensitive to carboxin than Basidiomycetes $(23,26)$. Moreover, the sensitivity of wild-type isolates to carboxin was lower compared to the sensitivity of the same isolates to boscalid. This finding showed that carboxin is less efficient than boscalid in controlling the wild-type sensitive isolates. However, carboxin expressed a strong fungicidal activity at high doses, inhibiting both highly boscalid-resistant and -sensitive isolates. These differences in efficacy between the two fungicides could result from differences in their intrinsic activity. Differences in levels of cross-resistance between fungicides due to differences in intrinsic activity have been reported for compounds that share same modes of action $(4,12,14)$. Even so, data from this study clearly revealed that all carboxin-resistant isolates have a different pattern of boscalid resistance compared to the carboxin-sensitive isolates and displayed relative high levels of cross resistance to boscalid. Thus, even though A. alternata appears to have a higher basal resistance towards carboxin, the results clearly showed that the boscalid-resistant mutants exhibit positive cross-resistance to carboxin.

The site of action of both boscalid and carboxin is reportedly in the Sdh complex of the electron transport pathway and in light of the cross resistance results (Table 1) it is tempting to speculate that carboxin and boscalid may share similar resistance mechanisms. In the case of carboxin, biochemical and molecular studies of laboratory isolates showed that resistance is caused by point mutations in target genes that cause target-site modifications $(3,10,13,15,22,26)$. In this study, to elucidate the molecular basis of boscalid-resistant phenotypes in A. alternata the iron sulphur subunit of the complex II was targeted for analysis. To initiate this work the gene encoding the A. alternata $S d h B$ subunit was sequenced. Comparison of the predicted amino acid sequence of AaSdhB from A. alternata with the $\mathrm{SdhB}$ from other fungi showed that this region is particularly conserved between fungal proteins. Analysis of the AaSdhB protein structure indicates high conservation of three cysteine-rich clusters associated with ironsulphur centers involved in electron transport. Sequence comparison of resistant isolates with those of the wild-type isolates showed that a single point mutation existed in fungicide-resistant A. alternata isolates. This mutation leads to a substitution of a highly conserved histidine residue, located in a region associated with the (3Fe-4 S) high-potential non-heme iron sulphur-redox (S3) center to either tyrosine (H277Y) or Arg (H277R). This finding is consistent with previously published reports in which a substitution of the conserved histidine residue was clearly demonstrated as the mechanism responsible for carboxin $(\mathrm{Cbx})$ resistance in $U$. maydis $(3,26)$. Structural analysis of the quinonebinding site (Q-site) undertaken on $E$. coli revealed two potential binding-positions; one potential Q-site was very close to the conserved histidine residue, suggesting a possible role in ubiquinone binding and reduction (11). Interestingly, the same study revealed that carboxin docked in the same way as ubiquinone in close proximity to the conserved histidine. These results strongly suggest that the histidine residue, in addition to its crucial role in ubiquinone binding, is essential for proper carboxamide (carboxin and boscalid) binding and thus their inhibitory action. The mutation responsible for the $\mathrm{H} 277 \mathrm{Y}$ substitution in the $A a S d h B$ gene is identical to that characterized in M. graminicolla Cbxresistant strains (26). More recently, Stammler et al. (28) reported that the same mutation was found within the iron sulphur gene homologue of boscalid-resistant field and laboratory mutants of B. cinerea. Furthermore, boscalid sensitivity losses were ascribed to this mutation. In the present study, results from sequencing resistant fungal strains were consolidated into PCR-based molecular diagnostic methods. Results indicating boscalid resistance in A. alternata strains using these molecular assays were in general agreement with results obtained from conventional bioassays. Thus, and in the light of studies made in other fungal species, it is inferred that the two mutations H277Y and/or H277R are associated with high levels of resistance to boscalid. The introduction of these mutant alleles in the wild-type strain would constitute an ultimate proof that these mutations are responsible for the observed phenotypes.

In some boscalid-resistant strains there was no variation in the DNA sequence of the $A a S d h B$ gene compared to the wild type. The absence of mutations in the $A a S d h B$ gene in the remaining strains that showed high level of boscalid resistance raised the possibility that mutation(s) in other loci are involved in the acquisition of the boscalid resistant phenotype. This assertion is not surprising since the mechanism of action of boscalid involves at least two other genes of the Sdh complex. Indeed, previous studies have shown that mutations in $S d h C$ or $S d h D$ determine resistance to carboxin and flutolanil $(13,22)$. As such, future work should attempt to isolate orthologues of these genes in A. alternata in order to further clarify the molecular basis of boscalid resistance. Moreover, another mutation has been detected in the $\mathrm{SdhB}$ sequence in B. cinerea (28) and it cannot be excluded that this particular genotype might also exist in the Alternaria populations.

The purpose of this study was not to dwell on the factors that could influence the development of boscalid resistance in $A$. alternata of pistachio. However, it was noted that even with the limited sampling of this study, there was variation in the frequency of the various resistance mutations. Further studies are needed to understand the behavior of mutants in pathogenicity assays in the presence or absence of a competitive wild-type population and in the presence or absence of fungicide treatments. Significantly, this study has produced molecular diagnostic methods that constitute reliable tests to identify boscalid-resistant isolates of Alternaria from pistachio and almond orchards. However, as mentioned above, more mutations than those characterized in this study are likely to contribute to boscalid resistance outbreaks. The characterization of A. alternata $S d h C$ and $S d h D$ genes is underway and will provide more robust molecular screening assays. This will ultimately lead to the development of efficient and sensitive molecular typing methods for the full spectrum of mutations causing boscalid resistance in A. alternata and will facilitate studies monitoring the relative frequencies of resistance phenotypes. These studies will provide information that is vital in the design of resistance management strategies.

\section{ACKNOWLEDGMENTS}

The authors thank D. P Morgan for technical assistance and for the collection of isolates from pistachio orchards, Chemtura Corp. for providing us with carboxin in the form of Vitavax $34 \mathrm{FF}$, and D. Davidson and C. Askew for critically reading the manuscript.

\section{LITERATURE CITED}

1. Avenot, H. F., and Michailides, T. J. 2007. Resistance to boscalid fungicide in Alternaria alternata isolates from pistachio in California. Plant Dis. 91:1345-1350.

2. Avenot, H., Morgan, D. P., and Michailides, T. J. 2008. Resistance to pyraclostrobin, boscalid and multiple resistance to Pristine (pyraclostrobin + boscalid) fungicide in Alternaria alternata causing alternaria late blight of pistachios in California. Plant Pathol. 57:135-140.

3. Broomfield, P. L. E., and Hargreaves, J. A. 1992. A single amino-acid change in the iron-sulphur protein subunit of succinate dehydrogenase confers resistance to carboxin in Ustilago maydis. Curr. Genet. 22:117-121.

4. Cohen, Y., and Gisi, U. 2007. Differential activity of carboxylic acid amide fungicides againstvarious developmental stages of Phytophthora infestans. Phytopathology 97:1274-1283.

5. Delp, C. J. 1980. Coping with resistance to plant disease agents. Plant Dis. 64:652-657.

6. Fungicide Resistance Action Committee. 2006. FRAC code List 2: Fungicides sorted by modes of action. Published online by FRAC. 
7. Georgopoulos, S. G., Alexandri, E., and Chrysayi, M. 1972. Genetic evidence for the action of oxathiin and thiazole derivatives on the succinic dehydrogenase system of Ustilago maydis mitochondria. J. Bacteriol. 110:809-817.

8. Georgopoulos, S. G., Chrysayi, M., and White, G. A. 1975. Carboxin resistance in haploid, the heterozygous diploid, and the plant-parasitic dicaryotic phase of Ustilago maydis. Pestic. Biochem. Phys. 5:543-551.

9. Gunatilleke, I., Arst, H. N., and Scazzocchio, C. 1976. Three genes determine the carboxin sensitivity of mitochondrial succinate oxidation in Aspergillus nidulans. Genet. Res. 26:297-305.

10. Honda, Y., Matsuyama, T., Irie, T., and Watanabe, T. 2000. Carboxin resistance transformation of the homobasidiomycete fungus Pleurotus ostreatus. Curr. Genet. 37:209-212.

11. Horsefield, R., Yankovskaya, V., Sexton, G., Whittingham, W., Shiomi, K., Omura, S., Byrne, B., Cecchini, G., and Iwata, S. 2006. Structural and computational analysis of the quinone-binding site of complex II (succinate-ubiquinone oxidoreductase): A mechanism of electron transfer and proton conduction during ubiquinone reduction. J. Biol. Chem 281:7309-7316.

12. Iacomi-Vasilescu, B., Avenot, H., Bataille-Simoneau, N., Laurent, E., Guenard, M., and Simoneau, P. 2004. In vitro fungicide sensitivity of Alternaria species pathogenic to crucifers and identification of Alternaria brassicicola field isolates highly resistant to both dicarboximides and phenylpyrroles. Crop Prot. 23:481-488.

13. Ito, Y., Muraguchi, H., Seshime, Y., Oita, S., and Yanagi, S. O. 2004. Flutolanil and carboxin resistance in Coprinus cinereus conferred by a mutation in the cytochrome $b_{560}$ subunit of succinate dehydrogenase complex (complex II). Mol. Genet. Genomics 272:328-335.

14. Karaoglanidis, G. S., and Thanassoulopoulos, C. C. 2003. Crossresistance patterns among sterol biosynthesis inhibiting fungicides (SBIs) in Cercospora beticola. Eur. J. Plant Pathol. 109:929-934.

15. Keon, J. P. R., White, G. A., and Hargreaves, J. A. 1991. Isolation, characterization and sequence of a gene conferring resistance to the systemic fungicide carboxin from the maize smut pathogen, Ustilago maydis. Curr. Genet. 19:475-481.

16. Kita, K., Takamiya, S., Furushima, R., Villagra, E., Wang, H., Aoki, T., Oya, H. 1991. Molecular organization of Complex II and its role in anaerobiosis. Prog. Neuropath.7:21-30.

17. Kuhn, P. J. 1984. Mode of action of carboximides. Symp. Ser. Br. Mycol. Soc. 9:155-183.

18. Kwok, S., Kellogg, D. E., McKinney, N., Spasic, D., Goda, L., Levenson, C., and Sninsky, J. J. 1990. Effects of primer-template mismatches on the polymerase chain reaction: Human immunodeficiency virus type 1 model studies. Nucleic Acids Res. 18:999-1005.

19. Ma, Z., Felts, D., and Michailides, T. J. 2003. Resistance to azoxystrobin in Alternaria isolates from pistachio in California. Pestic. Biochem. Phys. 77:66-74.

20. Matheron, M. E., and Porchas, M. 2004. Acitivity of boscalid, fenhexamid, fluazinam, fludioxonil, and vinclozolin on growth of Sclerotinia minor and S. sclerotiorum and development of lettuce drop. Plant Dis. 88:665-668.

21. Matsson, M., Ackrell, B. A., Cochran, B., and Hederstedt, L. 1998. Carboxin resistance in Paracoccus denitrificans conferred by a mutation in the membrane-anchor domain of succinate:quinine reductase. Arch. Microbiol. 170:27-37.

22. Matsson, M., and Hederstedt, L. 2001 The carboxin-binding site on Paracoccus denitrificans succinate:quinone reductase identified by mutations. J. Bioenerg. Biomembr. 33:99-105.

23. Motoba, K., Uchida, M., and Tada, E. 1988. Mode of antifungal action and selectivity of flutolanil. Agric. Biol. Chem. 52:1445-1449.

24. Old, J. M. 1991. Detection of mutations by the amplification refractory mutation system (ARMS). Method Mol. Biol. 9:77-84.

25. Pryor, B., and Michailides, T. J. 2002. Morphological, pathogenic, and molecular characterization of Alternaria isolates associated with Alternaria late blight of pistachio. Phytopathology 92:406-416.

26. Skinner, W., Bailey, A., Renwick, A., Keon, J., Gurr, S., and Hargreaves, J. 1998. A single amino-acid substitution in the iron-sulphur protein subunit of succinate dehydrogenase determines resistance to carboxin in Mycosphaerella graminicola. Curr. Genet. 34:393-398.

27. Spiegel, J., and Stammler, G. 2006. Baseline sensitivity of Monilinia laxa and $M$. fructigena to pyraclostrobin and boscalid. J. Plant Dis. Protect. 113:199-206.

28. Stammler, G., Brix, H. D., Glättli, A., Semar, M., and Schoefl, U. 2007. Biological properties of the carboxamide boscalid including recent studies on its mode of action. Pages 16-21 in: Proc. BCPC XVI Intr. Plant Prot. Cong. British Crop Protection Council Publications, Alton, Hampshire, UK.

29. Stammler, G., and Speakman, J. 2006. Microtiter method to test the sensitivity of Botrytis cinerea to boscalid. J. Phytopathol. 154:508-510.

30. Ulrich, J. T., and Mathre, D. E. 1972. Mode of action of oxathiin systemic fungicides. V. Effect on electron transport system of Ustilago maydis and Saccharomyces cerevisiae. J. Bacteriol. 110:628-632.

31. Yong, L., Ma, Z., Reyes, H. C., Morgan, D. P., and Michailides, T. J. 2007. Using real-time PCR to survey frequency of azoxystrobin-resistant allele G143A in Alternaria populations from almond and pistachio orchards in California. Pestic. Biochem Phys. 88:328-336. 